\title{
An editorial overview: HIV/AIDS in China
}

\author{
Richard Y ZHAO \\ University of Maryland School of Medicine, 10 South Pine Street, MSTF 700A, Baltimore, Maryland 21201, USA
}

China has come a long way in fighting against its HIV/AIDS epidemic. The Chinese government has taken an active role in combating this detrimental disease and such a welcome attitude by the Chinese government will certainly provide a positive spin on its effort in reducing the HIV/AIDS epidemic in China.

Nonetheless, China is facing an almost insurmountable challenge in fighting this epidemic. With nearly one million people already infected in the country, the infection rate has been steady in the range of 30\% since 1995 [1]. In 2001, reported number of HIV infections increased to $58 \%$ [2]. As of July of 2005, 57.5\% increase of registered HIV carriers was again recorded by the Chinese Ministry of Health [1]. The virus has spread to all 31 provinces, autonomous regions and municipalities. Under such an alarming infection rate, more than 10 million infected cases are projected by the end of this decade [3]. China has one fifth of the total world population, thus an increase of its HIV epidemic and the resulting social and economical consequences will have a significant impact on the global economy and social structures.

There are still reasons to be optimistic in reducing the HIV epidemic in China because of its unique patterns of HIV infection. First, HIV infection is currently limited to specific geographic areas (pockets) and special high- risk populations. Close to half (43.2\%) of the China's HIV infection cases are injection drug users (IDUs), which are predominantly populated in the Southwest of China in the areas of Yunnan and Guangxi provinces [4]. These two provinces are close to the notorious "Gold triangle", which is located along the boundaries of Burma (Myanmar), Laos and Thailand. Effective control of drug smuggling in this area should have a significant impact on reducing HIV infection via drug abuse. The second major transmission route, which has contributed to $26.8 \%$ of the total HIV infection, is commercial blood sales. Because of the repeated usage of needles for blood collection and re-transfusion of serum back to the blood donors, massive HIV infection was spread through tainted needles in Henan province and its vicinity [5]. Government cracks down on such unethical blood sales in these areas in recent years is believed to have reduced this route of transmission to a minimum level. Another $8.3 \%$ of the total HIV infection is due to heterosexual transmission. Homosexual transmission accounts for a small percentage (approx. 0.2\%) of HIV infection in China by 2001 [4].

Thus, China does have quite difficult challenges yet a unique window of opportunity to keep this fatal disease at bay? One of the most dangerous threats to the China's effort in reducing its HIV/AIDS epidemic at present is the possibility of changing its HIV transmission patterns from rural (pockets) to metropolitan (general population) areas; and from IDUs to heterosextrual transmission especially via prostitution. For example, it would be unthinkable had the AIDS virus penetrated into the prostitution industry in China. China currently has estimated number of ten million sex workers in 2001 [6]. HIV at the moment has not yet massively penetrated into this particular population. Because prostitution is illegal in China, it becomes especially a challenge to reach this population for HIV education and intervention. Hence creative and specific steps must be taken into account to access and educate this special high-risk population on how to prevent HIV transmission, i.e., volunteer counseling and testing (VCT) and condom use. Therefore, keys to limit spread of HIV in China are to block HIV transmission from rural special populations to metropolitan general populations, and further to prevent transmission from IDUs to heterosextrual transmission especially though prostitution. Achieving these goals requires comprehensive approaches and the involvement of the entire society, including all levels of governmental agencies, non-governmental organizations and all citizens. First, continued governmental commitment at all levels is essential for success. China is capable of launching successful nation-wide campaigns as it has been demonstrated in eliminating the 2003 SARS outbreak through a rapid and extensive nation-wide campaign. China has also successfully implemented a nation-wide birth control program over several decades in its goal to reduce its population. Second, prevention through public education is currently the only key to massively reduce viral transmission. Conceivably, 


\section{EDITORIAL}

government-led national campaign to publicize condom use for HIV infection control could potentially achieve costeffective yet rewarding outcome in minimizing this deadly disease in this country. Third, intervention of risky behaviors or treatment of already infected patients through active participation of medical professionals is equally important in minimizing the impact of the existing prevalence of this disease. Improved knowledge of diagnosis, treatment and patient care among point-of-care medical professionals could play a very important role in limiting the spread of this disease. Fourth, adaptations of successful strategies and avoiding the mistakes made by other countries through international collaborations have to be an integral part of this battle against the HIV/AIDS epidemic in China. Finally, active researches in understanding of the basic biology of the AIDS virus in an effort to find a cure or to develop a potent vaccine against this viral infection should be the ultimate goal of this pathogen-host or HIV/AIDS-human interaction.

The goal of this special issue is to systematically introduce the current situation of the HIV epidemic in China. Although it is not our intention to do so exhaustively, it covers epidemiology, social behavior, governmental policies, and roles of non-governmental organizations, patient care and treatment, as well as areas of basic science research. This special issue is intended to provide a comprehensive and primary scientific reference to those who are interested in HIV/ AIDS in China. To my knowledge, this is the first attempt in the scientific community to describe HIV/AIDS in China in such a comprehensive way through scientific publications. Another unique feature of this special issue is that all of the articles included here are contributed by experts in this special field.

As the editor of this special topic on "HIV/AIDS in China", I am especially indebted to Cell Research, a top-leading English journal based in China and part of the Nature journal family. Cell Research normally publishes only cell biologyrelated basic science articles. Because of the special status of the HIV epidemic in China, the editorial office of Cell Research has graciously agreed to publish such a special topic covering various disciplines that are not typically included in this journal.

Even though China is facing tremendous challenges in controlling its inevitable epidemic, I am optimistic about the prospects for control of HIV/AIDS in China. A government-led national campaign with the participation of all levels of appropriate organizations combined with international collaborations may very well creates yet another miracle in minimizing this deadly disease in this country.

\section{REFERENCES}

1 Daily, C. in China Daily, US Department of Health and Human Services, Beijing 2005.

2 CDC, C. in China Daily (Beijing, ed.), China Center for Disease Control and Prevention, Beijing 2004.

3 UNAIDS. in China Daily, pp. http://www.unaids.org/EN/Geographical+Area/by+country/china.asp, Joint United Nationsl Programme on HIV/AIDS, Beijing 2005.

4 CDC, C. in China Daily (Beijing, ed.), Vol. 1, Ministry of Health, Beijing 2003.

5 CDC, C. in China Daily (Beijing, ed.), Vol. 1, Sate Council AIDS Working Committee Office and UN Theme Group on HIV/AIDS in China, Beijing 2004.

6 International, U.P. in China Daily, pp. http://www.upi.com/inc/view.php? StoryID=20030104-095224-1418r, US Department of Health and Human Services, Beijing 2005.

Richard Y ZHAO, Ph.D. Associate Professor and Head Division of Molecular Pathology, Department of Pathology, Department of Microbiology-Immunology, University of Maryland School of Medicine, Institute of Human Virology, University of Maryland Biotechnology Institute;

Director, Molecular Diagnostics Laboratory, University of Maryland Medical System.

Tel: 410-706-6301; Fax: 410-706-6302; E-mail: rzhao@som.umaryland.edu 